\title{
Communication skills training for emergency department senior house officers-a qualitative study
}

\author{
Gavin Lloyd, Dave Skarratts, Neil Robinson, Cliff Reid
}

\begin{abstract}
Objective-To identify common weaknesses in senior house officer-patient consultation skills, and evaluate direct observation with feedback and negotiation of educational contracts, as a teaching tool in an emergency department setting.

Method-Common weaknesses were identified through review of feedback charts by three trained observers. Alteration in clinical and learning behaviour, as well as senior house officer and observer perceptions of the teaching were evaluated qualitatively by a combination of semistructured interviews and focus groups. Results-Several common weaknesses were identified, notably the use of closed questions, and poor negotiation and explanation of treatment plan and follow up. The senior house officers perceived improvement in their clinical practice, welcomed feedback, and subsequently set, though did not complete educational contracts. While comfortable with this style of teaching, the observers felt that it did not make efficient use of teaching time.

Conclusions-This study identifies common weaknesses in the consultation skills of emergency department senior house officers and confirms the need for training in this area. Direct observation is effective in changing behaviour to this end, though self directed learning is not necessarily stimulated. Video recorded consultations with group feedback may be a more effective teaching tool.

(F Accid Emerg Med 2000;17:246-250)
\end{abstract}

Keywords: communication; consultation; training

Effective communication between doctor and patient is a central clinical function that cannot be delegated. ${ }^{1}$ Treating every patient politely and considerately, listening to and respecting their views, giving them information in a way that they can understand, and respecting their right to be fully involved in decisions about their care are duties of doctors registered with the General Medical Council. ${ }^{2}$
A review of hospital-based surveys reported a mean dissatisfaction rate with medical communication of $38 \%,{ }^{3}$ though this is likely to be an underestimate. ${ }^{4}$ Most complaints by the public about emergency department (ED) doctors deal not with clinical competency but with communication ${ }^{5-8}$ and several malpractice allegations arise from communication error. ${ }^{9}$ Deficiencies are not confined to junior doctors, ${ }^{10}$ suggesting that experience alone does not necessarily lead to good communication skills. A study by Dale et al suggested that for a major part of their work in the ED, senior house officer (SHO) consultation techniques could be improved. ${ }^{11}$

Surveys of doctors have shown that the doctor-patient relationship causes considerable stress and anxiety because of the doctors' lack of confidence and competence in communicating well. ${ }^{12}{ }^{13}$ Such anxieties may be particularly acute in ED SHOs who are required to deal with a case mix that is relatively new to them including patients with minor injuries, primary care problems, and large numbers of children.

Good medical communication skills are feasible routinely in clinical practice and can be achieved during normal clinical encounters, without unduly prolonging them, provided that the clinician has learned the relevant techniques. ${ }^{14} 15$ They have been shown to improve both patient satisfaction ${ }^{16}$ and physical health. ${ }^{17}$ There is also good evidence to show that lasting changes in doctors' behaviour and communication skills are attainable. ${ }^{16-20}$

The teaching of communication skills at all levels of medical education is recommended by the General Medical Council, ${ }^{21}$ Audit Commission, ${ }^{22}$ international consensus ${ }^{1}$ and other parties. ${ }^{5-8} 23$

This study explores the use of direct observation of SHO-patient consultations with feedback from a senior doctor as a teaching tool in the ED setting.

The research questions posed are:

- what common weaknesses in SHO-patient consultations exist?

- does the teaching tool change clinical and learning behaviour?

- how is the teaching tool perceived by the SHOs and observers/senior doctors? 
Summary of consultation:

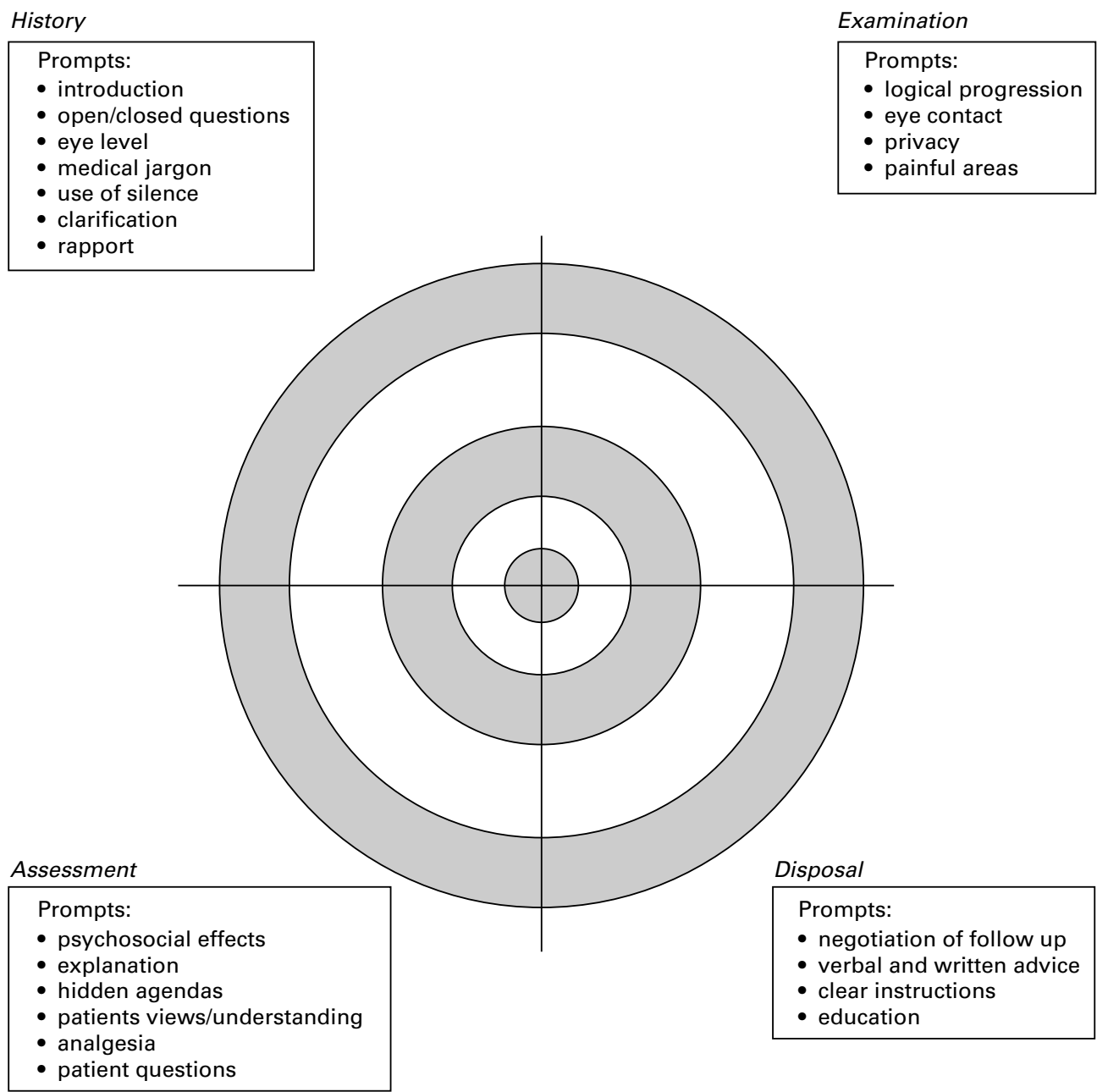

Challenge: low/medium/high

Major errors: yes/no minor errors: yes/no

Educational contract:

Place any favourable comments towards the centre of the target, less favourable comments towards the periphery, and any missing points from the consultation outside the target.

Figure 1 Feedback chart.

\section{Methods}

The direct observation procedure is outlined below.

- Observation of SHO-patient consultation

- Feedback elicited from SHO on their performance

- Observer feedback given to SHO (written and verbal)

- Negotiation of educational contracts

- Follow up of educational contracts

At the outset of the study each SHO was given a written outline of the teaching format and an opportunity to clarify any issues with an observer. Patients were selected to provide a stimulating case mix. Consent was not requested. After each consultation feedback was elicited away from the clinical area. In particular the observers encouraged reflection, explored the SHOs' thoughts and feelings and sought alternative behaviour in consultation skills, as well as investigating clinical reason. The observer then gave verbal and written feedback using the chart illustrated in figure 1. This chart, an adaptation of the validated assessment tool used in the membership examination of the Royal College of General Practitioners focuses on the four key areas of history, examination, assessment and disposal. Subsequently each SHO was encouraged to identify clinical learning needs, and make and later complete an educational contract with the observer. Finally a copy of 
the feedback chart was given to the $\mathrm{SHO}$ so as to reinforce comments made on communication skills.

This approach to teaching is a synthesis of problem-based interviewing devised at $\mathrm{Mc}$ Master University, ${ }^{24}$ and key elements from other models. ${ }^{25-27}$ All three observers were senior ED trainees who instructed in one or more advanced life support courses. Each had trained to give feedback in this fashion by piloting their skills on the preceding set of SHOs. Practice sessions were peer reviewed with comments invited from both $\mathrm{SHO}$ and fellow observer.

Common weaknesses in SHO consultation skills were identified through review of the feedback charts by all three observers. Any change in SHO behaviour was evaluated qualitatively through the process of triangulation (a combination of research methods designed to improve validity). ${ }^{29}$ Firstly, an independent skilled researcher from outside the department interviewed each $\mathrm{SHO}$ in a semi-structured format. The question content of the interview is outlined below.

- What are your views about observed sessions?

- What do you believe the benefits of the method to be?

- Have you changed your consultation skills as a result? If so how?

- Did you make any educational contracts? How did you feel?

- Does observation lead to or improve self directed learning?

- Was there anything you disliked about the process?

- Any other comments?

Individual interviews were tape recorded and transcribed systematically by the lead author and an independent reviewer. Common responses were further agreed with the interviewer.

Secondly, a focus group facilitated by the same researcher allowed the SHOs the opportunity to comment further and reach consensus on the questions posed. Finally, an observer focus group elicited any perceptions of change in SHO behaviour.

The value of the teaching tool as perceived by both SHOs and observers was evaluated by the same methods. In addition, attitudes towards the option of videoed consultations with group feedback were explored in the SHO focus group session.

\section{Results}

Forty SHO-patient consultations were observed between March and April 1998. All nine SHOs had been in post for a month before the onset of the study. Five had just completed their house officer post, one had six months SHO experience and three were third year SHOs, two of whom had completed six month ED posts previously. Only one of the junior doctors had had communication skills training as an undergraduate and none had as postgraduates.
COMMON WEAKNESSES

The common weaknesses observed in the SHO-patient consultations are listed below.

- Use of closed questions

- The house officer clerking style

- Use of medical jargon

- Poor negotiation and explanation of treatment plan and follow up care

- Limited advice

- Limited exploration of patients thoughts and concerns

- Poor approach to paediatric consultations

Most introductions by the SHOs were appropriate in establishing the basis of good doctor-patient rapport. This was improved by eye level consultations in the majority of cases. However, there was frequent use of closed questions, particularly as the opening question of any consultation. While no cases of domestic violence or non-accidental injury were apparently missed, the potential danger of a closed question strategy was explained in the SHO feedback. Furthermore, the misleading potential of a triage note in SHO data gathering was illustrated in some of the consultations-that is, the doctor would take the presenting complaint as read and explore no further.

The five SHOs who had recently completed their pre-registration training seemed to, and declared themselves more comfortable with medical rather than trauma cases. Each was observed to run a consultation along a house officer clerking style, rather than focusing on the patient's presenting complaint. These consultations were often inappropriately lengthy.

The weakest part of most observed consultations involved the explanation and negotiation of any treatment plan and follow up. Medical jargon was often used and little use was made of any supplementary written instructions. Advice with regard to return to work/school/ sport was sporadic. Patients thoughts and concerns were rarely explored- "do you have any questions?" or a similar enquiry was frequently absent.

Though only a few of the observed consultations involved children, it was apparent that establishing a rapport with them proved difficult. Failure to consult at eye level and to make use of the designated children's room were observed in some cases. The strategy for exploring the potential of a non-accidental injury could have been improved by the SHOs in all cases, for example, by gaining the child's confidence with straight forward closed questions (name, age, etc) before directing an open enquiry as to the nature of the accident to the child and not to the accompanying adult. In addition when examining children there was little instruction in the use of distraction techniques for either a parent or a named nurse.

\section{CHANGE IN SHO BEHAVIOUR}

The SHOs perceived that they had changed their practice as a result of the study. Having been encouraged to reflect on their observed consultations the SHOs had begun to analyse their consultation skills routinely. Specific examples of changed practice included regularly offering analgesia, asking the patient if 
there were any questions, explaining treatment plans and clear exploration and discussion of patient follow up care. Improvements in communication skills were observed as the study progressed. Many of the SHOs began to identify their own learning needs, setting educational "contracts" for themselves. None of these reached completion on inquiry.

SHO AND OBSERVER PERCEPTIONS OF THE TEACHING TOOL

Each of the SHOs felt that they had benefited from the teaching experience and they welcomed the feedback they received. In particular they valued the emphasis on the good points of their communication skills, which they felt built confidence and raised self esteem. A common comment made was that feedback was rare outside the context of the study unless an error had been made. On the observers' part each consultation generated several points for discussion, not only in terms of communication skills but also in diagnostic reasoning. In addition the SHOs were poor at identifying many of their errors in consultations.

The SHOs were generally supportive of the idea of educational contracts. "It helps to have directed learning", was one of the comments (though the observers' aim had been to promote self directed learning). However, completion of those contracts negotiated between SHO and observer was varied, being incompatible with a busy ED schedule according to some SHOs. The observers' perception was that those SHOs keen to learn had completed their educational contracts regardless.

There was initial concern by both SHOs and observers that direct observation would prove intimidating and indeed some SHOs found the experience uncomfortable. Most felt that their performance was changed by being observed by a senior doctor, some suggesting that they were more thorough than usual, others that the senior doctor made them feel nervous. Similarly the observers' perception was that the study was not well received by some of the SHOs and that they treated it like an examination. Junior doctor anxiety however was perceived to diminish as the study progressed. All observers felt comfortable giving feedback and were able to adapt life support instructor skills to the study. "It is easy to forget what you were like as an SHO" was a salutary comment.

Other points raised by the SHOs included the suggestion that this type of teaching should be part of medical student training, and that it is particularly useful in fostering a change from the regimented clerking style used as house officers to the consultation skills required as an ED SHO.

The observers felt that the study did not make efficient use of teaching time. Each consultation and feedback episode would take up to 40 minutes, making this type of teaching impractical at times when the department was busy. As most of the weaknesses in communication skills were common to all SHOs it was proposed that videoed consultations with feed- back to the group would make much better use of valuable time and allow each $\mathrm{SHO}$ a better opportunity to critically review their performance. The SHOs themselves felt comfortable with the concept of videoed consultation with feedback in a group setting.

Finally, should other parties use the written feedback chart, the observers recommended a modification using prompts for each quadrant. Figure 1 represents a modified chart with suggested comments for the observer, rather than the original used in the study.

\section{Discussion}

Direct observation represents a valid method of identifying weaknesses in consultation skills, as the ED SHOs are observed in their natural setting. It overcomes the discrepancy between what the SHO says (perhaps in presenting their findings to a senior colleague) or writes (as elicited in the auditing of patient records) and what they actually do. While many senior ED doctors may routinely observe or overhear in part junior doctor-patient consultations, direct observation offers a structured format for analysing and giving feedback on SHO performance. Allied to this is an approach to encouraging reflection and the setting and completion of educational contracts. Though SHO behaviour may be modified by observation - the so called Hawthorn effect ${ }^{29}$ - it is difficult to argue that video recording might not do the same.

The frequency of consultation errors has not been measured as the study was geared towards the provision of a stimulating nonrandomised case mix. The list of common weaknesses therefore represents generalisations, and indeed each observer's subjective perceptions may have been influenced by experiences from outside the study.

The teaching seems to be effective in changing clinical behaviour. A scientifically robust methodology for measuring any change was not however selected, because such a strategy would have been complex, costly and might importantly have been considered as threatening. Though this educational tool seems to have encouraged reflection, its ability to stimulate self directed learning (as measured by the number of educational contracts set by and completed by the SHOs) seems limited.

The SHOs clearly valued the teaching, though the potential for bias in their responses is acknowledged. The potential benefits of video recording consultations with group feedback over direct observation may include increased self awareness, peer review and improved efficiency in terms of teaching time. It may however be limited by cost, technical problems (especially with regards to sound recording), vulnerability of the equipment in an ED setting and ethical considerations, particularly where patient examinations or aggressive or violent patients are concerned. Training needs for the facilitators of group feedback may also be required. In addition, SHOs may be threatened by group review ${ }^{12}$ though this study suggested otherwise.

Alternative methods in teaching communication skills include the use of role play and 
tape recording of consultations as described by Dale et al. ${ }^{12}$ In addition, standardised patients and standardised videos may be used, neither of which has been explored in the ED setting. This study would suggest a particular need for the latter in teaching communication skills for doctor-child consultations.

By aiming to increase reflection and self directed learning, direct observation and feedback has much in common with the service-based learning model for ED SHO training. ${ }^{30}$ Integration within any existing teaching and appraisal programme would improve many of the goals of this teaching tool.

A further application may include the observation of ED trainee-patient consultations by a consultant or peer. A careful selection of challenging patients may maximise the benefit of direct observation in this format.

\section{Conclusion}

This study identifies common weaknesses in the consultation skills of ED SHOs and confirms the need for training in this area. Direct observation is effective in changing SHO behaviour to this end though self directed learning is not necessarily stimulated. Video recorded consultations with group feedback may be a more effective teaching tool.

We would like to acknowledge the helpful comments made by Mr Andrew Swain on the presentation of this work. Our thanks go to all the senior house officers who participated in the study.

Contributors

Gavin Lloyd initiated and coordinated the study, acted as one of the three observers, participated in the observer focus group discussion, transcribed the tape recordings of individual SHO interviews, and wrote the paper. Dave Skarretts acted as the interviewer for the SHOs both individually and as a focus group, transcribed the focus group discussion and contributed towards editing the paper. Neil Robinson and Cliff Reid acted as observers, participated in the observer focus group discussion and contributed towards editing the paper. Gavin Lloyd acts as guarantor of the study.

Funding: none.

Conflicts of interest: none.

1 Simpson M, Buckman R, Stewart M, et al. Doctor-patient communication: the Toronto Consensus Statement. BMf 1991;303:1385-7.

2 General Medical Council. Good medical practice. London: GMC, 1998.

3 Ley P. Communicating with patients. London: Croom Helm, 1988 .

4 Fallowfield LJ. The ideal consultation. Br F Hosp Med 1992; 47:364-7.

5 Richmond PW, Evans RC. Complaints and litigation. Three years at a busy accident and emergency department 1983 85. Health Trends 1989;21:42-5.
6 Reichl M, Sleet RA. Complaints against accident and emergency department: current trends. Arch Emerg Med 1990;7: 246-8.

7 Hunt MT, Glucksman ME. A review of 7 years of complaints in an inner-city accident and emergency department. Arch Emerg Med 1991;8:17-23.

8 Kadzombe EA, Coals J. Complaints against doctors in and accident and emergency department: a ten year analysis. Arch Emerg Med 1992;9:134-42.

9 Shapiro RS, Simpson DE, Lawrence SL, et al. A survey of sued and non-sued physicians and suing patients. Arch Intern Med 1989;149:2190-6.

10 Byrne PS, Long BEL. Doctors talking to patients. London: Royal College of General Practitioners, 1984.

11 Dale J, Green J, Reid F, et al. Primary care in the accident and emergency department II: comparison of general practitioners and hospital doctors. BMF 1995;311:427-30.

12 Fallowfield LJ, Davis H. Organisational and training issues. In: Davis H, Fallowfield LJ, eds. Counselling and communication in health care. Chichester: John Wiley, 1991:317-42.

13 Greco RS, Pittenger RA. One man's practice: effects of developing insight on doctor-patient transactions. London: Tavistock, 1966

14 Stewart MA, Brown JB, Weston WW. Patient-centered interviewing part III: five provocative questions. Can Fam Physician 1989;35:159-61.

15 Dale J, Davies M, Vassant K, et al. Primary care consultation skills training: implementing a new training programme for senior house officers in an accident and emergency department. Med Educ 1997;31:243-9.

16 Ong LM, de Haes JC, Hoos AM, et al. Doctor-patient communication : a review of the literature. Soc Sci Med 1995;40:903-18.

17 Stewart MA. Effective physician-patient communication and health outcomes: a review. Can Med Assoc F 1995;152: 1423-33.

18 Levinson W, Roter DL. The effects of two continuing medical education programs on communication skills of practising primary health care physicians. F Gen Intern Med 1993; 8:318-24.

19 Davis DA, Thomson MA, Oxman AD, et al. Changing physician performance. A systematic review of the effect of continuing medical education strategies. $7 A M A$ 1995;274: $700-5$.

20 Maguire P, Fairbairn S, Fletcher C. Consultation skills of young doctors: benefits of feedback training in interviewing as students persist [correction appears in BMF 1986;293: 26]. BMF 1986;292:1573-6.

21 General Medical Council. Protecting patients, guiding doctors. Annual review 1998. London: General Medical Council.

22 Audit Commission. What seems to be the matter: communication between hospitals and patients. London: HMSO, 1993.

23 Meryn S. Improving doctor-patient communication. BMF 1998;316:1922.

24 Lesser AL. Problem-based interviewing in general practice: a model. Med Educ 1985;19:299-304.

25 Pratt D, Magill MK. Educational contracts: a basis for effective clinical teaching. Fournal of Medical Education 1983;58:462-7.

26 The Royal College of General Practitioners. Tutorial styles. A working party. London: RCGP, 1972.

27 Alexander RH, Procter HJ. Advanced trauma life support: instructor manual. Chicago: American College of Surgeons, 1993.

28 Greenhalgh T, Taylor R. How to read a paper. Papers that go beyond numbers (qualitative research). BMF 1997;315: $740-3$.

29 Roethlisberger FJ, Dickson WJ. Management and the worker. Cambridge, MA: Harvard University Press, 1939.

30 Grant J, Marsden P. Service based learning. London: Joint Centre for Education in Medicine, 1995. 